\title{
Continuous structural health monitoring of selected geotechnical quantities within Kościuszko Mound in Cracow
}

\author{
Rafat Sieńko ${ }^{1, *}$, Lukasz Bednarski ${ }^{2}$, and Tomasz Howiacki ${ }^{1}$ \\ ${ }^{1}$ Cracow University of Technology, Warszawska 24, 31-155 Kraków, Poland \\ ${ }^{2}$ AGH University of Science and Technology, Al. Mickiewicza 30, 30-059, Poland
}

\begin{abstract}
Kościuszko Mound in Cracow is earthen structure particularly susceptible to deformations, among other things, due to the unfavourable physical and mechanical properties of the ground and a significant tilt of slopes. Since the beginning of its existence to the present day, structural failures were repeatedly occurred, and the biggest took place after 1997, when heavy rains led to the greatest destruction of the entire mound solid ever. Overall renovation, however, did not produced the expected results and did not stop negative atmospheric influences on the monument behaviour. Therefore, in 2012, structural health mo nitoring was installed on-site, providing remote, continuous and automatic measurements of selected physical quantities, which are important from mound technical condition point of view. System is measuring, among other things, changes in vertical displacements, circumferential and radial deformations, ground pore pressure of water within a mound body and humidity of its surface layers. Correlation of results from geodetic, inclinometer and meteorological (derived from the weather station which is part of the monitoring system) measurements will enable a comprehensive assessment of ground layer work mechanisms within the whole mound solid and will be one of the bases for effective strengthening design in the future.
\end{abstract}

\section{Introduction}

Kosciuszko Mound in Cracow is a unique geotechnical structure, because of its geometry and material, but also for historical and tourist aspects. To this day it is a symbol of free and independent Poland, the National Monument, which annually attracts thousands of tourists from all over the world. The mound was raised on the hill of Blessed Bronisława in Cracow between 1820 and 1823 [1] in order to commemorate the outstanding Polish and American hero, general and engineer - Tadeusz Kościuszko, whose name is now worn by the Cracow University of Technology.

*Corresponding author: rsienko@pk.edu.pl 

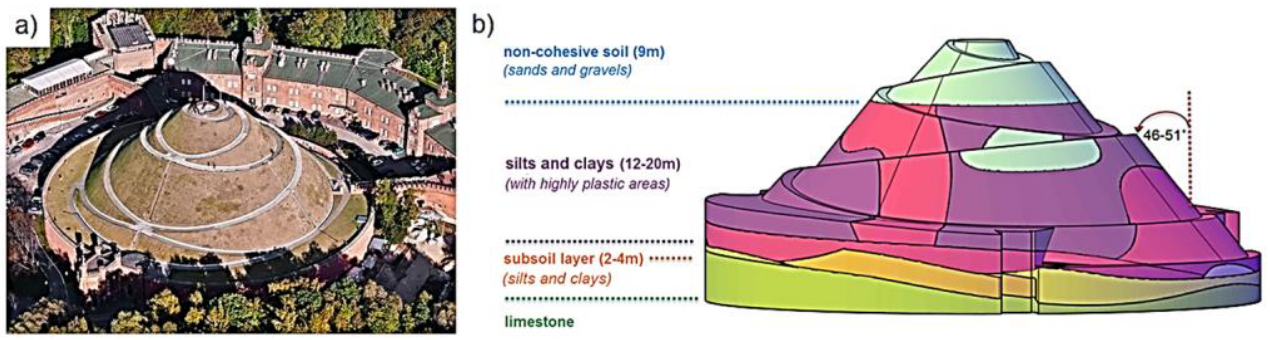

Fig. 1. Kościuszko mound: a) view [5]; b) visualization of ground layers [own elaboration].

The object under the assumption of builders was meant to be a symbol of durability, which cannot be destroyed neither by enemies nor time. Unfortunately, both the construction method and the building material used for this purpose have caused the structure to be susceptible to atmospheric influences. The mound was raised mainly using silt and clays, which are sensitive to water actions. Under the influence of hydrostatic pressure, the particles of soil move and organize, which has resulted in the past and result today in significant deformations of the mound body. Another important thing is steep slope, which exceeds (in some places more than twice) the angle of internal friction of such kind of grounds. This fact makes the Kościuszko Mound in Krakow a unique geotechnical structure worldwide. The shape of the limestone ceiling (inclination to the east) located in the immediate subsoil of the building, and the geometry of the surrounding brick wall (tholobate), which is indeed lower at the eastern side, are also significant for main directions of ground displacements.

\section{Damages and failures of Kościuszko Mound}

In the past, the solid of Kościuszko Mound has been destroyed many times, mainly in the form of landslides, cracks, ruptures and path damages through which rain water could freely enter the structure interior. Prior to 1979, no significant geological research was carried out, as well as engineering works that would improve the technical condition of the facility. Activities which were done were limited to determining the type ground in the superficial layers and describing damages resulting from the external loads. In the later period, until 1997, a number of minor repairs were performed. Among others, ruptures were sealed with clay, irrigation system was built and mechanical slope protection was applied by micropile palisade and ground anchor system. Unfortunately, all repairs proved to be ineffective, primarily because they were designed with incomplete recognition of the geological profile of the mound and did not constitute a comprehensive repair. 

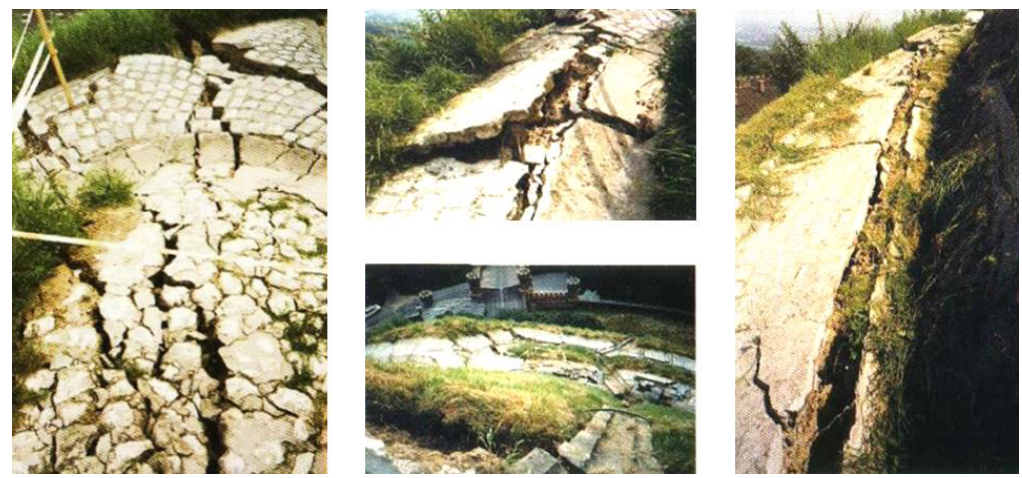

Fig. 2. Damages of Kościuszko Mound after flood in 1997 [1].

Large-scale repairs were carried out only after the 1997 flood, when the technical condition of the mound has been recognized as structural disaster. After its completion, about 50 geodetic benchmarks were installed on the mound peripheries as well as 4 inclinometer tubes. On the basis of vertical and horizontal displacement measurements it was found that for the next 10 years, the mound top settled about $0.50 \mathrm{~m}$ and moved in the east about $0.20 \mathrm{~m}$. It means that repairs did not stop the mass movements. Similarly to previous strengthening, designers did not have a full geotechnical documentation of deeper layers of the mound body.
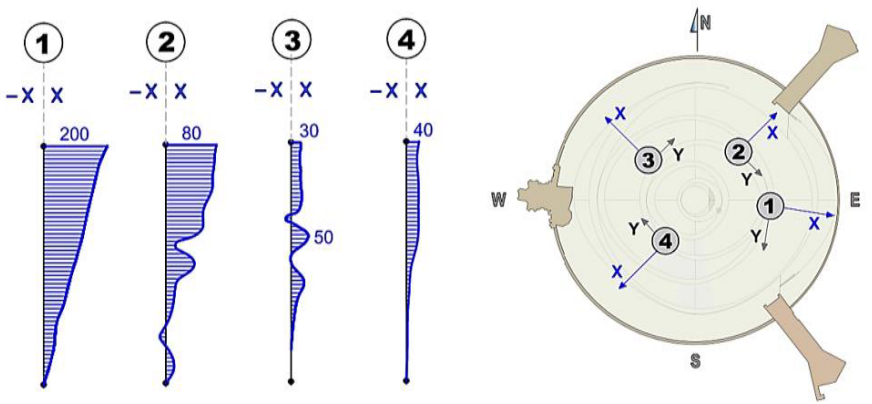

Fig. 3. Selected displacement profiles [mm] from inclinometer measurements between 2012-2014 [own elaboration].

\section{Structural health monitoring system}

Currently the condition of the monument allows for its normal operation, although surface layers sliding and slope erosion are locally observed. The underperformance of earlier repairs and the progressive degradation of the mound as a result of environmental impacts (the biggest during the floods in 2010) necessitate the development of solutions which aim is to protect the monument from another catastrophe and ensure its safe operation for next decades. For this reason, in 2012, while performing geological-engineering studies within the whole solid of mound and hill of Blessed Bronisława, it was decided to install an automatic measuring system, which allows to observe and control the work of whole volume of the mound in real-time. Continuous measurement of selected physical quantities is intended to indicate the mechanisms of monument destruction. 
One of the basic assumptions of structural health monitoring system design was to recognize the work of ground layers inside the body to perform a full three-dimensional analysis of its structural behavior. [2] It was decided to measure vertical displacements including changes in the thickness of selected soil layers (vertical extensometers), horizontal deformations (circumferential and radial), as well as changes in ground water pressure, soil humidity and temperature. Applied sensors are based on vibrating wire technology, which, thanks to its advantages (accuracy, resistance to external conditions, time stability) is widely used in long-term measurement systems $[3,4,5,6]$.
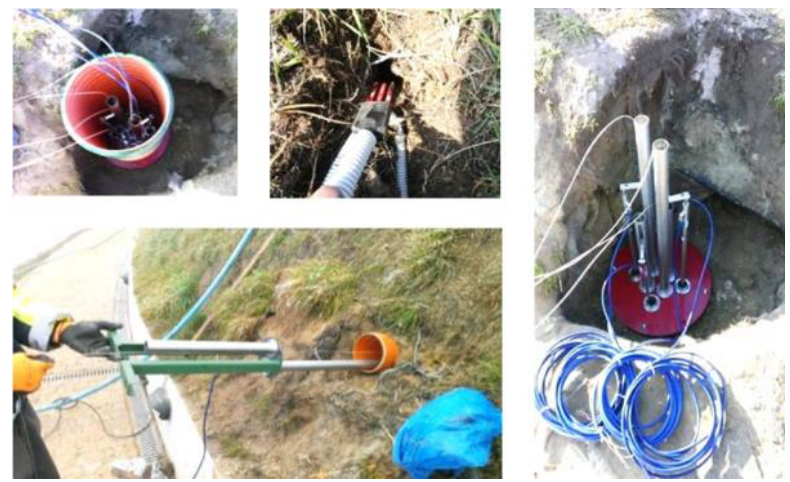

Fig. 4. Installation of SHM within Kościuszko Mound in Cracow [courtesy of SHM System].

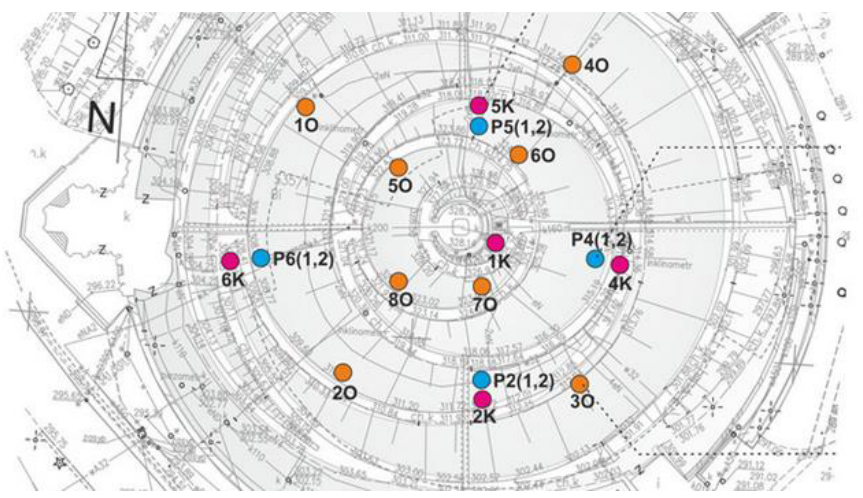

Fig. 5. Localization of measuring points („K”- vertical displacements, „O”- horizontal displacements (circumferential and radial) and ground humidity; „P” - ground water pressure and temperature) [courtesy of SHM System].

Measurements of vertical displacement are performed by means of tendon extensometers (Fig. 6a) in five locations. Details of its operation principle, sample data and results interpretation are presented in Chapter 4. Measurements of horizontal deformation are carried out by extensometers installed circumferentially along the peripheral surface and radially inside the body (Figure 6b). Located in eight places, sensors have measuring bases of $2000 \mathrm{~mm}$ (radial extensometers) and $1000 \mathrm{~mm}$ (peripheral extensometers). As the main active cause of Kościuszko Mound deformation is water infiltration and the associated change in soil moisture, within SHM system at four measuring points and three different depths, vibrating wire piezometers were installed (Figure 6c). 
a)

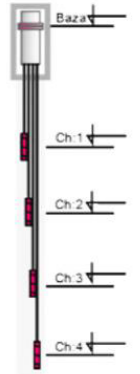

b)

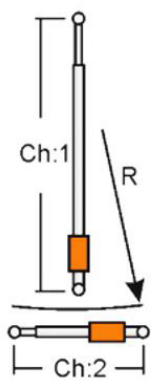

c)

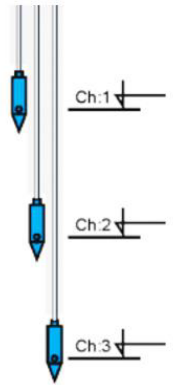

Fig. 6. Measuring sets: a) vertical extensometers, b) horizontal extensometers, c) piezometers [courtesy of SHM System].

All vibrating wire sensors are equipped with thermistors for parallel temperature measurements. This allows for thermal compensation of measuring data and for evaluation of temperature impact on the global response of geotechnical structure $[7,8]$.

The above-described elements of the SHM system should be assigned to structural (technical) monitoring subsystem. In 2014 the installation was supplemented with meteorological monitoring. A weather station consisting of a rain gauge, anemometer, air relative humidity and temperature sensor and pyranometer were installed. Obtained information about atmospheric conditions within the mound (precipitation, sunshine, wind force and direction) can be correlated with data obtaining from the building interior, which will allow to construct dependence between the external environment influences and the behavior of the whole body.

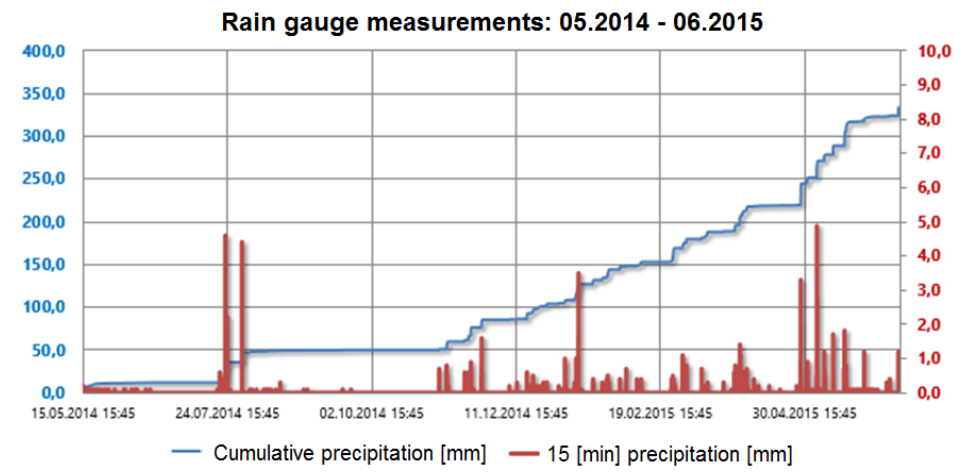

Fig. 7. Exemplary plot of the amount of precipitation [courtesy of SHM System].

The SHM system of the automatically performs measurements and archives data every 15 minutes from 2012 and eventually next over several decades. All data are converted according to the developed procedures and the results in tabular and graphical form (graphs) are displayed on the screen of any computer with Internet access. 


\section{Vertical extensometers}

Extensometric sensors allow for determination of defined segments lengths and they are often used in geotechnical measurements [9]. Within the monitoring system, five extensometers were installed, each consisting of four sensors. One end of a particular displacement sensor is attached to the surface of the mound perimeter (base) and the second, through a stainless steel tendon, is anchored inside the body at various depths - Fig. 7. Changes in the displacement of the base are determined by geodetic measurements, so it is possible to determine absolute changes in thickness of selected ground layers within the analyzed vertical measuring line. The rock ceiling was assumed as a fixed, unmovable reference, so the deformations of five layers are analyzed in a given vertical. The change in length recorded by sensor 1 will be included in the measurement of the length change recorded by sensor 2. Analogously, measurements are made by other sensors. By subtracting the individual displacement values, we obtain changes in the thickness of the ground layers. The sum of the thickness changes of the four layers is equal to the direct value of displacement resulting from measurement carried out by the sensor with the longest tendon (no. 4). If this value is subtracted from the base displacement, we will get information about the displacement of the extensometer anchor.
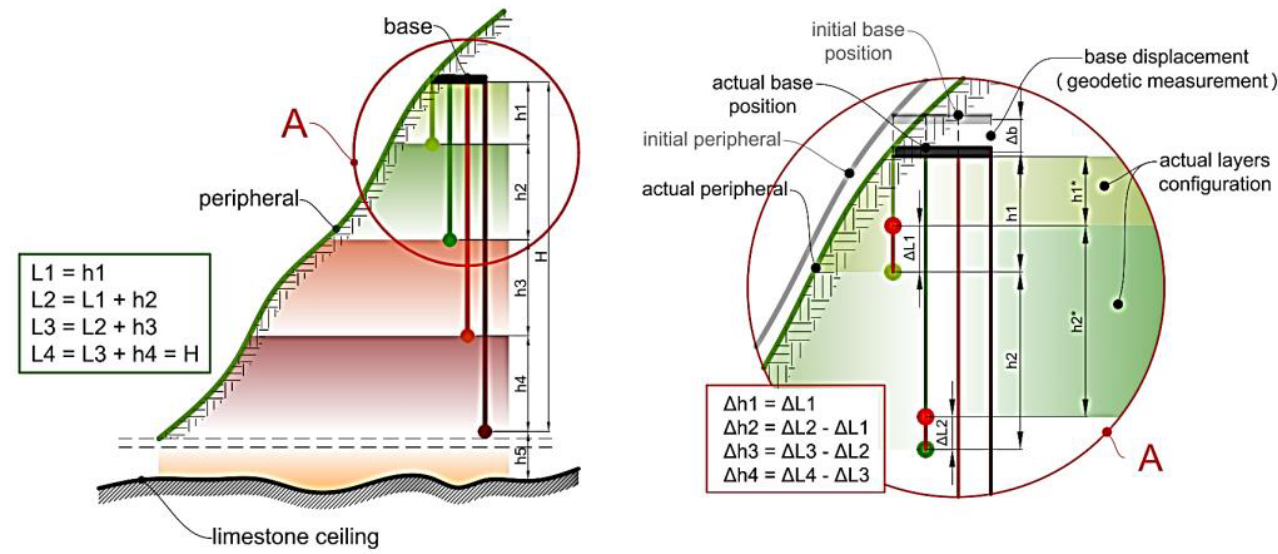

Fig. 8. Construction and operation principle of vertical extensometers [own elaboration].

The sum of the thicknesses $h_{i}{ }^{*}$ of all layers (from the rock to surface) in the current configuration will be equal to the sum of the initial thicknesses $h_{i}$ of the layers minus the base offset $\Delta b$.

$$
\Sigma h_{\mathrm{i}}^{*}=\Sigma h_{\mathrm{i}}^{*}-\Delta b
$$

Knowing the change in length $\Delta H$ measured by sensor 4 and base displacement $\Delta b$, we can determine the change in the thickness of the lowest ground layer $\Delta X$ lying directly above the limestone layer.

$$
\Delta X=\Delta b-\Delta H
$$


Table 1. The changes of ground layers [mm] between $06.2013-09.2014$

\begin{tabular}{|c|c|c|c|c|c|}
\hline Point & $\mathbf{\Delta h 1}$ & $\mathbf{\Delta h 2}$ & $\mathbf{\Delta h 3}$ & $\mathbf{\Delta h 4}$ & $\mathbf{\Sigma}=\mathbf{\Delta H}$ \\
\hline 1K & 4,84 & 0,96 & 12,82 & $-12,77$ & $\mathbf{5 , 8 5}$ \\
\hline 2K & 4,96 & $-0,81$ & 2,47 & $-1,94$ & $\mathbf{4 , 6 7}$ \\
\hline 4K & 6,91 & 1,46 & 0,65 & $-0,49$ & $\mathbf{8 , 5 3}$ \\
\hline 5K & 1,32 & 0,52 & $-2,96$ & 0,07 & $-\mathbf{1 , 0 5}$ \\
\hline 6K & 3,06 & 0,70 & 0,44 & $-0,90$ & $\mathbf{3 , 3 1}$ \\
\hline
\end{tabular}

It is worth to notice that the behavior of particular ground layers from which the mound was built is dependent on the depth. It is interesting that the thickness of certain layers is increased (red color and the minus sign in Table 1), which may indicate the presence of bulging soils. Nevertheless, during the entire considered period, there was a systematic decrease in the height of the extensometers bases. A qualitative graphical visualization of changes in the thickness of particular ground layers over a given period of time is shown in Figure 8 .

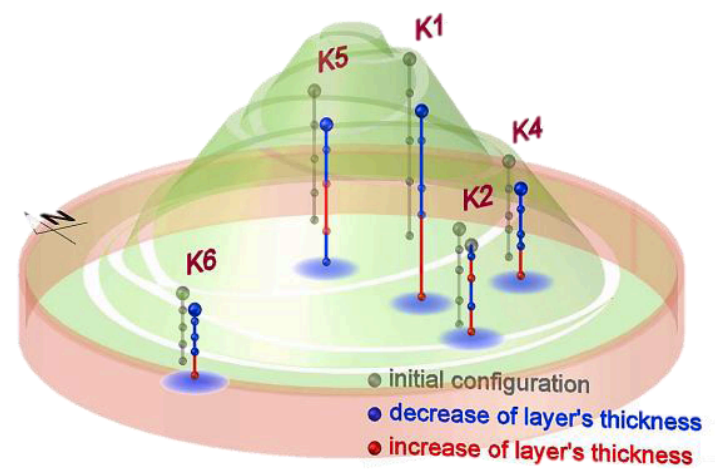

Fig. 9. Visualization of ground layers thicknesses changes between 06.2013 and 09.2014 [own elaboration].

Geodetic measurements showed the largest subsidence of $\mathrm{K} 1$ base during analyzed period. It was $26 \mathrm{~mm}$. Base K2 and K6 moved vertically by $7 \mathrm{~mm}$ and base K4 and K 5 by $13 \mathrm{~mm}$. The largest displacement measured by the K1 extensometer results, among others, from the location closest to the vertical central axis of the mound body. Concentration of the largest ground masses in this area generates the largest subsidence - Fig. 9.

The analyzed section at K5 (northern slope) was the only one with a slight elongation, but it was accompanied by a noticeable decrease in the base position by $13 \mathrm{~mm}$ as well as by the longest tendon anchor by $14 \mathrm{~mm}$. The elongation of the section results in the reduction of the thickness of the lowest layer (located directly above the rock). This deformation can be caused by washing away silt and clays from mound solid and moving them into limestone rock crevices.

\section{Conclusions}

The structural health monitoring system installed on the Kościuszko Mound in Cracow automatically provides information regarding selected physical quantities associated with the mound behavior. The qualitative and quantitative analysis of SHM data, geodetic, 
inclinometer and meteorological measurements is intended to help answer the question how to permanently protect the Monument against progressive degradation.

The monitoring system described in this paper is an example of how geotechnical design can be supported by in-situ measurements. Certain geoscientific problems require such kind of measurements, since classical geological recognition is insufficient. It is worth to remember that data acquisition about mechanical properties of the ground from the test takes place at any given time, whereas, due to different influences, these parameters may change over the time. SHM systems can actually enrich this information.

SHM systems allow to observe the structural work during construction process, reconstruction or during operation. The system described in this paper is also intented to perform such kind of function. Thanks to the results obtained from automatic sensors, it will be possible to verify the design assumptions and theoretical analyzes with in-situ measurements. This approach to geotechnical design is recommended by EN 1997 [10].

Currently, increased application of structural health monitoring systems in geotechnical issues is being observed in Poland. This phenomenon is in line with global trends, where most of the large and complex structures made from the ground, whose destruction consequences would be very significant, are equipped with measuring devices that allow for continuous observation of their behavior over time and quick reaction in case of unpredictable phenomenon.

\section{References}

1. Rokosz M., Katastrofa Kopca Kościuszki w 1997 roku i pierwsze próby ratowania zabytku (Kraków, 2007)

2. Dunnicliff J., Geotechnical instrumentation for monitoring field performance (John Wiley \& Sons, 1988)

3. Bednarski Ł., Sieńko R., Inżynieria i Budownictwo 11, 615 (2013)

4. Bednarski Ł., Sieńko R., Howiacki T., Procedia Engineering 108, 536 (2015)

5. Bednarski Ł., Sieńko R., Howiacki T., Cement-Lime-Concrete 6, 396 (2014)

6. Bordes J.L., Debreuille P.J., T.R.B. Record No. 1004, 20 (1985)

7. Lucas D. R., Fankhauser K., Springman S. M., Engineering Geology 219, 32 (2017)

8. Florin V. A., Industrial Services 47 (2), 12 (2013)

9. Sieńko R., I Konferencja Naukowo-Techniczna: Problematyka Projektowania $i$ Wykonawstwa w Aspekcie Nowych Technologii, Materiałów i Nowoczesnej Techniki w Budownictwie "TECH-BUD 2013" (Kraków 2013)

10. EN 1997, Eurocode 7, Geotechnical Design 